\title{
Effects on Soil Organic Carbon and Microbial Biomass Carbon of Different Tillage
}

\author{
Zhichen Yang ${ }^{1}$, Hong $\mathrm{Li}^{1}$, Jinshun Bai ${ }^{2}$ \\ ${ }^{1}$ Institute of Agricultural Integrated Development, Beijing Academy of Agricultural and Forest Science, Beijing, China, \\ 100097 \\ ${ }^{2}$ Key Laboratory of Plant Nutrition and Fertilizer, Ministry of Agriculture Institute of Agricultural Resources and Regional \\ Planning, Chinese Academy of Agricultural Sciences, Beijing, China, 100094
}

\begin{abstract}
To research data of soil organic carbon content and Soil microbial biomass carbon of different tillage, the results show that less tillage measures could significantly increase the active soil organic carbon content and Soil microbial biomass carbon. In addition, the contribution to increase organic carbon and microbial biomass carbon is much higher under the straw return treatment than no straw return. Dynamic change of microbial biomass carbon in each tillage treatment is in 4-7 months, have the same trend, but in August and September showed the opposite trend compared plowing tillage with rotary tillage and zero tillage
\end{abstract}

Keywords-different tillage; soil organic carbon; microbial biomass carbon.

\section{INTRODUCTION}

Changes in soil organic matter is more uncertain due to changes in farm management practices, especially in long-term changes. Therefore, under different soi l organic matter content, soil texture, type and amount of fertilizer, crop rotations and crop production levels, different researchers often draw controversial conclusions.

Studies have shown that, compared with conventional tillage, Zero tillage and Minimum tillage can significantly improve soil organic matter content. The reason for this situation is the input of soil active carbon increases, the loss of carbon reduction, that means an increase in soil carbon pooling, CO2 emission reduction. Meanwhile Zero tillage and Minimum tillage can reduces soil erosion and soil organic matter. Beare et al (1993) considers Zero tillage and Minimum tillage can promote growth of mycorrhizal fungi and fungi, at the same time, significantly increased soil microbial biomass and microbial species which can be fixed more unstable carbon accumulation, reduce the loss caused by mineralization; also conducive to the formation of large aggregates body.[1] Microbial utilization of organic carbon is a important characteristics which reflect the quality of the soil, the higher the efficiency, the less energy which required to maintain the same microbial, indicating the soil environment conducive to microbial growth, relatively high quality [2]. microbial biomass carbon is not only an important part, but also the driving force of the soil carbon cycle [3].

But studies also have shown that Zero tillage and Minimum tillage is not significant to improve soil carbon storage. Freixo et al (2002) found that, after 13 years of farming trials under conventional tillage, topsoil organic carbon of $0 \sim 5 \mathrm{~cm}$ reduced by $60 \%$, while Zero tillage conditions reduce 43\%; There was no significant difference[4,5] between the two farming methods in soil organic carbon under 5cm soil. Doran et al (1998) study showed that in wheat / fallow mode, zero tillage also lead to loss of topsoil carbon, that only by increasing cropping index and decrease the frequency of fallow, increasing the soil organic carbon inputs to soil, to reduce the loss rate of organic matter, or even increase it[6,7,8]. In this study, we study the change and transformation of soil carbon and microbial biomass carbon in long-term positioning experiments under different tillage systems to explore the effect on soil carbon of conservation tillage.

\section{MATERIALS AND METHODS}

\section{A. Experimental zone overview}

Testing ground in Taolin village Xing Shou town of Changping District, Beijing, the region belongs to the plains, semi-arid temperate continental monsoon climate, with four distinct seasons throughout the year; region's annual average temperature of $11.8{ }^{\circ} \mathrm{C}$; annual average rainfall of $579.1 \mathrm{~mm}$; The soil of pilot area is soil with fertility, good soil physical properties, the overall loose, good storage performance, strong water retention capacity.

\section{B. Experimental treatment}

Experimental treatments show in Tab.I 
TABLE I. EXPERIMENT SET UP OF LONG-TERM CONSERVATION TILLAGE EXPERIMENTAL STATION IN LUANCHENG

\begin{tabular}{|l|l|}
\hline treatments & Tillage and straw return methods \\
\hline F1 & $\begin{array}{l}\text { after harvest, orn stalks take out of the field, } \\
\text { plowing after the first spin, and then seeding and } \\
\text { harrowing (plowing depth 20cm) }\end{array}$ \\
\hline F2 & $\begin{array}{l}\text { Crushed corn stalks and return after harvest, } \\
\text { plowing after the first spin, and then seeding and } \\
\text { harrowing (plowing depth 20cm) }\end{array}$ \\
\hline $\mathrm{X}$ & $\begin{array}{l}\text { Crushed corn stalks and return after harvest, with } \\
\text { a rotary tiller for secondary crushing and spin } \\
\text { (Rotary deep 10cm) }\end{array}$ \\
\hline $\mathrm{M}$ & $\begin{array}{l}\text { Upright stalks natural distribution in farmland, } \\
\text { using no-till planter crushed straw, planting, } \\
\text { fertilizing and repression at the same time }\end{array}$ \\
\hline
\end{tabular}

\section{Sampling and analysis methods}

Sampling time: October 2010

Sampling method: Collect sample with Soil auger in 0-10 $\mathrm{cm}, 10-20 \mathrm{~cm}$ soil, for each treatment were randomly selected three replicates of five points, taking a mixed sample. After the samples were dried, over $0.25 \mathrm{~mm}$ sieve spare.

External heating potassium dichromate volumetric method for the determination of organic carbon, Microbial biomass carbon using a modified chloroform fumigation[9].

Statistics and analysis. Data using SPSS11.0 statistical software and Microsoft Excel 2000, using SPSS11.0 statistical software for data analysis of variance, with the method of least significant difference (LSD) for multiple comparison.

\section{RESULTS AND ANALYSIS}

\section{A. Soil organic carbon}

TABLE II. SOIL ORGANIC CARBON CONTENT UNDER DIFFERENT TILLAGES $\left(\mathrm{G} \mathrm{KG}^{-1}\right)$

\begin{tabular}{ccccc}
\hline & \multicolumn{5}{c}{ Treatments } \\
Soil depth(cm) & \multicolumn{5}{c}{ F1 } & F2 & X & M \\
\cline { 2 - 5 } & $9.324 \mathrm{c}$ & $9.988 \mathrm{bc}$ & $13.886 \mathrm{a}$ & $10.612 \mathrm{bc}$ \\
& & & & \\
\hline $5-10$ & $10.127 \mathrm{ab}$ & $11.120 \mathrm{a}$ & $9.498 \mathrm{ab}$ & $8.308 \mathrm{~b}$ \\
& & & & \\
$10-20$ & $8.308 \mathrm{a}$ & $5.699 \mathrm{~b}$ & $7.021 \mathrm{ab}$ & $5.387 \mathrm{~b}$ \\
& & & & \\
$20-30$ & $4.307 \mathrm{~b}$ & $4.434 \mathrm{~b}$ & $4.579 \mathrm{~b}$ & $3.782 \mathrm{~b}$ \\
\hline
\end{tabular}

Notes: Values followed by a different letter are significantly different at $5 \%$ level based on LSD test.

Table 2 shows: For $0-5 \mathrm{~cm}$ soil layer, there are significant differences between $\mathrm{X}$ and F1, F2, M, however, no significant difference between the F2, F1 and M, which shows in $0-5 \mathrm{~cm}$ soil, spin tillage greatest impact on soil organic carbon. This is because all of rotary tillage which break the straw to the soil and mix it, so the rotary tillage treatment contains a lot of straw in $0-10 \mathrm{~cm}$ soil, when the straw decompose, organic carbon content will increase. Although there are a lot of straw on ground under Zero tillage treatment (M), but only covers the ground, and not mixed with the soil and so the organic carbon content of the $0-5 \mathrm{~cm}$ soil layer is not much. There is no significant difference on soil organic carbon content in the $0-5 \mathrm{~cm}$ soil with straw returning or not undre Conventional tillage treatment. This is due to the plowing depth is $20 \mathrm{~cm}$, on the one hand straw have been overturned lower and in the surface layer is relatively small, on the other hand, due to the great disturbance of soil, increasing the surface soil aeration, so that organic matter mineralization rate increases, reducing the accumulation of organic carbon in the surface layer. Thus, different tillage practices on soil organic carbon on the surface is different.

For $5-10 \mathrm{~cm}$ soil layer, there are significant differences between F2 and M, the difference between F2 and other treatments is not significant, between $\mathrm{M}$ and other treatments, the differences were not significant too. Because F2 processing has broken stalks and mixed with soil in $0-20 \mathrm{~cm}$ soil layer, so there were crushed stalks in the $0-20 \mathrm{~cm}$ soil, which helps increase the organic carbon content, $M$ processing is pushed straw aside while sowing, straw exist on the surface, in the soil of $5-10 \mathrm{~cm}$, the amount of straw in $\mathrm{M}$ processing is less than $\mathrm{F} 2$, so the the difference of organic matter content between $\mathrm{M}$ and F2 is significant.

In $10-20 \mathrm{~cm}$ soil layer, there is a significant difference between $\mathrm{F} 1$ and F2, M, the difference between F2, M, X is not significant. For $\mathrm{M}$ and $\mathrm{X}$ tillage practices, due to the soil disturbance is very small, so there is no significant difference in organic carbon content between them, and F2 has the same amount of straw return with $\mathrm{M}, \mathrm{X}$, and plowed to a depth of $20 \mathrm{~cm}$, so the organic carbon content has an average trend in $0-20 \mathrm{~cm}$ soil, so there was no significant difference between F2, M, X in $10-20 \mathrm{~cm}$.

In $20-30 \mathrm{~cm}$ soil layer, the difference between the treatment is not significant, because the plough layer is generally $0-20 \mathrm{~cm}$, and under $20 \mathrm{~cm}$, there is almost no disturbance, so a variety of tillage measures in $20-30 \mathrm{~cm}$ soil layer has little effect, so the soil organic carbon is relatively stable.

$\mathrm{X}$ and $\mathrm{M}$ treatment compared to F1, F2 treatmen, soil organic carbon content reduced with increasing of soil depth; This is because $\mathrm{X}, \mathrm{M}$ treatments has a minimal soil disturbance, so the organic carbon content is basically a natural distribution with top-down dwindling, this is similar to previous studies. Zero tillage can protect the soil structure, reducing the decomposition of organic matter, and increased soil permeability, promoting the decomposition of organic matter, so at $0-5 \mathrm{~cm}$ soil layer, the soil organic carbon content of zero tillage treatment is high. In $5-10 \mathrm{~cm}$ soil layer, plowing the straw and other organic matter into the soil, increasing the organic carbon content of the soil. Thus, violently disturbed soil applied more important impact on 
soil organic carbon than organic matter return under farming measures.

\section{B. Soil microbial biomass carbon}

To understand the impact on soil properties of various tillage practices, soil microbial biomass carbon were monitored and obtained microbial biomass carbon data from April 28 to July 28 under various farming methods, The results are shown in Table III.

TABLE III. SOIL MICROBIAL BIOMASS CARBON AT DIFFERENT PERIOD UNDER DIFFERENT TILLAGES (MG KG-1)

\begin{tabular}{|c|c|c|c|c|}
\hline \multirow[t]{2}{*}{ Treatments } & \multicolumn{4}{|c|}{ microbial biomass carbon (mg·kg-1) } \\
\hline & April 28 & May 28 & June 28 & July 28 \\
\hline $\mathrm{F} 1$ & $219.46 c$ & $211.18 c$ & $186.78 b$ & $253.22 b$ \\
\hline F2 & $321.22 \mathrm{ab}$ & $260.27 b c$ & $229.58 b$ & $252.94 b$ \\
\hline M & $343.21 \mathrm{a}$ & $326.70 a$ & 239.51b & $310.20 \mathrm{ab}$ \\
\hline $\mathrm{X}$ & $343.78 a$ & 307.91ab & 292.43a & $337.54 \mathrm{a}$ \\
\hline
\end{tabular}

Notes: Values followed by a different superscript letter are significantly different at 5\% level based on LSD test.

See the results of these four months, the soil microbial biomass carbon were no significant differences between F1 and F2, M and $\mathrm{X}$ is same, but there is significant difference between $\mathrm{M}, \mathrm{X}$ and $\mathrm{F} 1$. This suggests that different tillage methods, have a greater impact on soil microbial. Compared with conventional tillage methods (F1) rotary tillage $(\mathrm{X})$ and zero tillage (M) with smaller soil disturbance can significantly improve the microbial biomass. This may be due to although plow can increased ventilation capacity of the soil, but the attendant was a large loss of soil moisture which produced a great inhibition on soil microbial growth and leading a lower soil microbial biomass carbon than $\mathrm{X}$ and $\mathrm{M}$ treatments; Correspondingly, the effect of rotary and zero tillage on soil disturbance is small, thus protecting the microbes living environment more suitable for microbial growth.

The experimental results show that the wheat corn cropping area of North China, straw will help improve the microbial carbon content in the topsoil; and Zero tillage and Minimum tillage help to improve the content of the soil microbial carbon in the topsoil, tillage reduces soil microbial biomass carbon in the topsoil. Dynamic change of microbial biomass carbon in each tillage treatment is in 4-7 months, have the same trend, but in August and September showed the opposite trend compared plowing tillage with rotary tillage and zero tillage, Figure1.

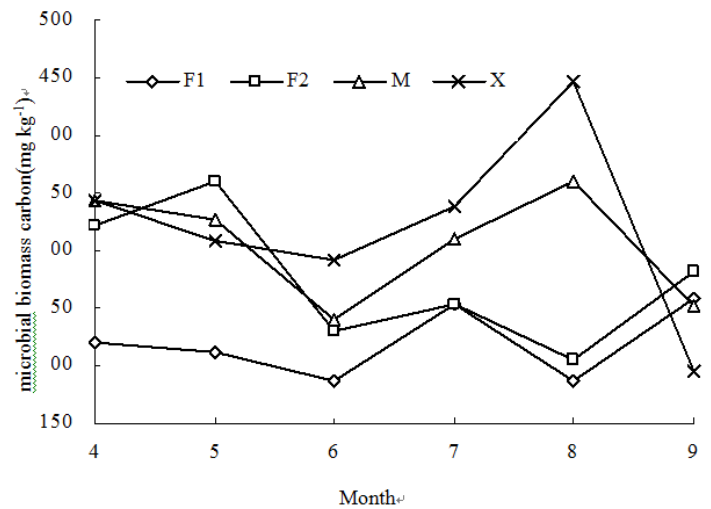

Figure 1. Soil microbial biomass dynamic at 0-20 cm depth under different tillage methods

In April, the rapid growth of wheat roots, moderate temperatures is conducive to microbial activity, so microbial biomass carbon have reached a higher peak in each treatment, and there is not significant difference between F1, F2, and X, M. no-till, zero tillage is highest $343.21 \mathrm{mg} \mathrm{kg}-1$, straw return is higher than no straw return treatments. This may be due to the straw return can provide a carbon source for microbial growth and to stimulate the growth of microorganisms.

In late May, microbial biomass carbon were declined in all three treatments except F1, this may be because the growth of wheat is peaked and into the filling stage, a significant increase in the demand for nitrogen, forming nitrogen dispute situation in plants and microorganisms, and thus inhibit microbial growth, which compared to the end of April, microbial biomass carbon decreased significantly.

At the end of June, there is a significant reduction of microbial biomass carbon in each treatment, this may be because, on the one hand the wheat has been harvested in mid-June, at the end of June, temperatures is higher, wheat stubble begins to decompose, requires a lot of nitrogen; on the other hand corn just beginning to grow, need more soil nutrients especially nitrogen, microbial compete resources with plant, therefore, although the soil temperature reaches the value of a suitable microbial growth, but in the absence of sufficient resources, microbial growth was inhibited, resulting in a microbial growth trough.

In the end of July, microbial biomass carbon of each treatment was increased. This may be because in this time, the soil temperature is higher, the maize growth is peak, increased root exudates provides the resources for microbial growth, on the other hand wheat straw decomposition gradually increase, which provided resources for the soil microorganisms growth, in such ideal situation with good resources and temperature, the soil microorganism grow rapidly.

In the end of August, different tillage showed a completely different trend. F1 microbial biomass carbon decreased rapidly, F2 treatment microbial biomass carbon remained stable, microbial biomass carbon of $\mathrm{X}$ and $\mathrm{M}$ treatment were significantly increased, especially $\mathrm{X}$ deal, 
reached $447.14 \mathrm{mg} \mathrm{kg}-1$. This may be related to the temperature of the soil, because in the end of August, high temperatures resulting in high temperatures within the soil, the microorganism in the case of too high temperature and too low will loss activity and inhibit microorganisms growth. Tillage measures disturbance on soil is large and increase the porosity of plow layer soil, so soil water and heat conditions so greatly affected by the outside world; rotary tillage and zero tillage disturbance is very small in soil , so the soil affected by the outside world is relatively small, so in the end of August, although the temperature is high, but has little effect on the temperature of the soil, and maintained a more suitable soil microbial growth temperature within the interior, this resulting in higher microbial biomass carbon content.

In the end of September, microbial biomass carbon between different treatment also showed the opposite trend, which may also related to soil aeration and temperature. It can be seen from the figure, at the end of September, F1 and F2 treatments microbial biomass carbon were improved, and $\mathrm{M}$ and $\mathrm{X}$ were all decreased, and four processing microbial biomass carbon achieve a more consistent level. This may be because in the end of September, as the temperature decreases, microbial activity gradually reduced, reaches a more balanced state, the impact of different tillage on microbial factors also weakened, and therefore, the performance of different tillage microbial biomass carbon gradually return to substantially the same level.

\section{CONCLUSIONS}

$\mathrm{X}$ and $\mathrm{M}$ treatment compared to tillage treatment, soil organic carbon content reduced with soil depth increasing; this is because these two measures soil disturbance is minimum, so the organic carbon content is basically a gradual reduction of natural distribution, thisn is similar to previous studies. And zero tillage can protect the soil structure, reducing the decomposition of organic matter, but tillage increased soil permeability, promoting the decomposition of organic matter, so at $0-5 \mathrm{~cm}$ soil layer, the soil organic carbon content of zero tillage treatment is high. In $5-10 \mathrm{~cm}$ soil layer, plowing can take straw and other organic matter into the soil, increas the soil organic carbon content. Thus, farming measures applied impact on soil organic carbon not only due to take organic matter into soil, more importantly, due to disturb soil violently.

The experimental results show that the wheat corn cropping area of North China, straw will help improve the microbial carbon content in the topsoil; and Zero tillage and Minimum tillage help to improve the content of the soil microbial carbon in the topsoil, tillage reduces soil microbial biomass carbon in the topsoil. Dynamic change of microbial biomass carbon in each tillage treatment is in 4-7 months, have the same trend, but in August and September showed the opposite trend compared plowing tillage with rotary tillage and zero tillage.

\section{V.ACKNOWLEDGEMENTS}

This study was financed by the Scientific research fund for young of Beijing Academy of Agricultural and Forest Science (QNJJ201425).

\section{REFERENCES}

[1] Beare MH, Pohland BR, Wright DH. Residue placement and fungicide effects on fungal communities in conventional and notillage soils. Soil Science Society of America Journal, 1993, 57: 392 399.

[2] Xianli Zhao, Guohong Lu, Qingyu Jia, etc. Advances in soil microbial biomass. Journal of Meteorology and Environment, 2006, 22 (4): 68 72

[3] Wei Jia, Haiping Zhou, Chun Guan, etc. Effects of Long- term Returning Corn Stalks to the Field Combined with Applying Fertilizer in Autumn on Microbial Biomass C, N and Enzyme Activity in Cinnamon Soil. Acta Agriculturae Boreali-Sinica, 2008,23(2):138 142

[4] Freixo AA, Machado PL, Santos HP. Soil organic carbon and fractions of a Rhodic Ferralsol under the influence of tillage and crop rotation systems in southern Brazi. Soil and Tillage Research, 2002, 64: 221 231.

[5] Doran.Defining soil quality for a sustainable environment soil society of America publication. Soil Biology and Biochemistry ,1994, (35) :3

[6] Doran JW, Elliott ET, Paustian K. Soil microbial activity, nitrogencycling, and long-term changes in organic carbon pools as related to fallow tillage management. Soil and Tillage Research, 1998, 49:3 18.

[7] Campbell CA, Selles F, Lafond GP. Adopting zero tillage management: Impact on soil $\mathrm{C}$ and $\mathrm{N}$ under long-term crop rotations in a thin Black Chernozem. Canadian Journal of Soil Science, 2001, 81: 39 148.

[8] Yang LX, Pan JJ. Dynamics models of soil organic carbon. Journal of Forestry Research, 2003, 14 (4): 323 330.

[9] Wu Jinshui, LIN Qi-mei, Huang Qiaoyun, soil microbial biomass measurement method and its applications. Meteorological Press, 2006 